${ }^{1}$ Departamento de Fitotecnia, Universidade Federal de Alagoas (UFAL), Av. Manoel Severino Barbosa, Bom Sucesso, CEP:57309-005, Arapiraca, AL, Brasil

* autor correspondente $\triangle$ ricardoufal2010@gmail.com

\section{Caracterização e produtividade de cultivares de milho doce em fileiras duplas sob diferentes espaçamentos entre plantas}

\author{
Characterization and yield of double-row sweet corn cultivars \\ under different plant spacings
}

Maria Helena da Paz Miranda Silva' ${ }^{1}$ J José Djalma Messias dos Santos', Thainá Araújo de Oliveira', Rodrigo Pereira Silva' ${ }^{1}$, Antônio Lucrécio dos Santos Neto ${ }^{1}$, Ademāria Aparecida de Souza', Ricardo Barros Silva ${ }^{*}$, Gleica Maria Correia Martins
RESUMO: Neste trabalho, o objetivo foi caracterizar e avaliar o desempenho produtivo de cultivares de milho doce sob diferentes espaçamentos entre plantas em fileiras duplas na região Agreste do estado Alagoas. O plantio foi feito em blocos casualizados, com quatro repetições. Os tratamentos foram quatro espaçamentos entre plantas (20, 25,30 e $35 \mathrm{~cm}$ ), com espaçamentos entre linhas simples e duplas de 0,25 e $0,75 \mathrm{~m}$, respectivamente, e duas cultivares de milho doce (SV9298 PRO e Thunder). As variáveis avaliadas foram: diâmetro e comprimento de espigas sem palha, número de fileiras de grãos por espigas, número de grãos por fileira de espigas, produtividade de espigas sem palha e de grãos, $\mathrm{pH}$ e teor de brix de grãos. Os dados obtidos foram submetidos à análise de variância $(\mathrm{P}<0,05)$. A cultivar de milho doce $\mathrm{SV} 9298$ PRO produz espigas de maior comprimento (20,2 $\mathrm{cm})$, diâmetro $(52,1 \mathrm{~mm})$ e produtividade de grãos $\left(13,3\right.$ tha $\left.^{-1}\right)$. As características pós-colheita de $\mathrm{pH}$ e teor de brix são maiores em áreas cultivadas com SV9298 PRO, sendo, respectivamente, 7,0 e $13,5^{\circ}$ Brix. O espaçamento entre plantas de $35 \mathrm{~cm}$ promoveu a produção de espigas sem palha com maior comprimento $(19,5 \mathrm{~cm})$ e diâmetro $(52,3 \mathrm{~mm})$. A maior produtividade de grãos foi de $14,2 \mathrm{t} \mathrm{ha}^{-1}$, e foi obtida com o espaçamento entre plantas de $35 \mathrm{~cm}$. De maneira geral, a cultivar SV9298 PRO apresentou desempenho produtivo superior em relação a Thunder, e o espaçamento de $35 \mathrm{~cm}$ entre plantas proporciona maior produtividade de grãos.

PALAVRAS-CHAVE: Zea mays L var. saccharata, densidade populacional, produtividade de grãos.
ABSTRACT: In this work, the objective was to characterize and evaluate the productive performance of sweet corn cultivars under different spacing between plants in double-rows in the region Agreste of Alagoas state. The planting was done in randomized blocks, with four replications. The treatments were four plant spacings (20,25, 30 , and $35 \mathrm{~cm})$, with spacing between single and double lines of 0.25 and $0.75 \mathrm{~m}$, respectively, and two sweet corn cultivars (SV9298 PRO and Thunder). The variables evaluated were diameter and length of ears without straw, number of rows of grains per ear, number of grains per row of ears, the productivity of ears without straw and grains, $p H$, and brix content. The data obtained were submitted to analysis of variance $(p<0.05)$. The sweet corn cultivar SV9298 PRO produces ears of greater length $(20.2 \mathrm{~cm})$, diameter $(52.1 \mathrm{~mm})$, and grain yield (13.3 $\left.\mathrm{Mg} \mathrm{ha}^{-1}\right)$. The postharvest characteristics of $p H$ and brix content are higher in areas cultivated with SV9298 PRO, being, respectively, 7.0 and $13.5^{\circ}$ Brix. The spacing between plants of $35 \mathrm{~cm}$ promoted the production ears without straw with greater length $(19.5 \mathrm{~cm})$ and diameter $(52.3 \mathrm{~mm})$. The highest grain yield was 14.2 $\mathrm{Mg} \mathrm{ha}^{-1}$, obtained with the spacing between plants of $35 \mathrm{~cm}$. In general, the cultivar SV9298 PRO showed superior productive performance to Thunder, and the spacing of $35 \mathrm{~cm}$ between plants provides greater grain productivity.

KEYWORDS: Zea mays L var. saccharata, population density, grain yield.

\section{Introdução}

O milho doce (Zea mays var. saccharata) é uma hortaliça de cultivo intensivo socioeconomicamente importante, por gerar emprego e renda em todo o mundo (LUZ et al., 2014). 
Diferencia-se do milho comum por possuir genes que afetam a biossíntese de carboidratos no endosperma de seus grãos, o que eleva seu teor de açúcares e reduz a concentração de amido, tornando-o apreciável como milho verde (CARVALHO; NAKAGAWA, 2012; ZUCARELI et al., 2014).

De acordo com a Organização das Nações Unidas para Agricultura e Alimentação (FOOD AND AGRICULTURE ORGANIZATION, 2012), em 2018 foram produzidas 9,1 milhões de toneladas de milho verde no mundo, com produtividade média de apenas $8,1 \mathrm{tha}^{-1}$. Essa baixa produtividade é proporcionada pelo fato de cultivos ocorrerem, principalmente, sob baixo índice tecnológico, como, por exemplo, sem adubação e irrigação, plantio em espaçamentos inadequados e uso de cultivares pouco produtivas. Especificamente no Brasil são poucas pesquisas voltadas para o cultivo do milho doce, o que agrava o cenário nacional. No país, $90 \%$ da área cultivada de milho doce fica localizada no estado de Goiás (BRASIL, 2018). O estado de Alagoas tem potencial para o cultivo de milho doce por estar inserido no Leste do Nordeste brasileiro, região que possui clima favorável para o cultivo da planta, caracterizada por apresentar temperatura média anual $25^{\circ} \mathrm{C}$, alta disponibilidade de radiação solar durante o ano e precipitação pluvial anual média que varia de 1.000 a $1.500 \mathrm{~mm}$, a qual atende à demanda hídrica da cultura (BARROS et al., 2012).

Desse modo, a adoção de técnicas eficientes de manejo, como a escolha de cultivares mais produtivas e plantio em espaçamento adequado, surgem como promissores métodos para o aumento do índice tecnológico em cultivos de milho doce e, consequentemente, o incremento produtivo e a expansão da cultura em todo o país. Entretanto, atualmente existem apenas duas cultivares transgênicas de milho doce registradas no Brasil (SV9298 PRO e Thunder), com restrita distribuição, o que limita a expansão da área cultivada no país (BRASIL, 2020), pois a escolha da cultivar é um dos principais fatores que influenciam a produtividade do milho em uma determinada região, sendo responsável por até $50 \%$ do rendimento produtivo obtido (PEREIRA FILHO; BORGHI, 2018). Portanto, a identificação de cultivares mais produtiva nas diversas regiões do país torna-se importante para difusão do milho doce e aumento da produção nacional.

Além da escolha da cultivar, a densidade populacional de plantas também interfere no desempenho produtivo do milho doce. Pesquisadores afirmam que a redução do espaçamento entre plantas eleva o número de plantas por área e contribui para maior produtividade, sendo essa uma tendência nas principais regiões produtoras do país (MANTOVANI et al., 2015; SILVA et al., 2020). Assim, o planejamento e utilização de técnicas mais eficientes de cultivo são importantes na otimização dos sistemas agrícolas e na exploração do potencial produtivo do milho doce.

Diante do exposto, observa-se que há potencial de expansão das áreas de cultivo do milho doce no Brasil e aumento da produção nacional, entretanto, é necessário desenvolver pesquisas que busquem aumentar a eficiência no manejo da cultura, como a utilização de espaçamentos entre plantas que proporcione maiores produtividades e cultivares aptas às regiões brasileiras, a exemplo do Nordeste brasileiro. Por isso, o objetivo neste trabalho foi avaliar o efeito de diferentes espaçamentos de plantio entre plantas no desempenho produtivo das cultivares de milho doce SV9298 PRO e Thunder no Agreste de Alagoas.

\section{Material e Métodos}

$\mathrm{O}$ experimento foi realizado no município de Arapiraca, Agreste de Alagoas ( $9^{\circ} 48^{\prime} 48^{\prime \prime}$ S, 36 36 $36^{\prime} 21^{\prime \prime} \mathrm{W}, 260 \mathrm{~m}$ ), entre julho e setembro de 2018. De acordo com a classificação climática de Koppen (1948), o clima da região Agreste é do tipo AS tropical, com temperatura anual média de $25{ }^{\circ} \mathrm{C}$ e precipitação pluvial anual média de $800 \mathrm{~mm}$, distribuídos de forma sazonal, com maior concentração nos meses de maio a julho, e existência de um verão seco.

Dados agrometeorológicos do período de cultivo foram obtidos através de estação agrometeorológica automática do Instituto Nacional de Meteorologia (INMET) instalada em Arapiraca. A temperatura do ar média $\left(\mathrm{T}_{\mathrm{MED}}\right)$, durante o período experimental, foi de $24,4{ }^{\circ} \mathrm{C}$, que variou de $21,7{ }^{\circ} \mathrm{C}$ (04 de julho) a $27,5^{\circ} \mathrm{C}$ (17 de setembro). A precipitação pluvial acumulada durante o período experimental foi de $119 \mathrm{~mm}$, sendo registrado no dia 10 de setembro o maior acúmulo diário de chuva, $20 \mathrm{~mm}$ (Figura 1).

O preparo do solo foi realizado através de duas gradagens, aos 30 e 05 dias antes da semeadura. As propriedades químicas do solo da área experimental na camada de 0 a 0,2 m estão representadas na Tabela 1.

$\mathrm{O}$ delineamento experimental utilizado foi em blocos casualizados (DBC), com cinco repetições. Os tratamentos foram duas cultivares de milho doce (SV9298 PRO e Thunder) e quatro espaçamentos entre plantas em fileiras duplas $(20,25$, 30 e $35 \mathrm{~cm}$ ), e assim foi formado um esquema fatorial $2 \times 4$, totalizando 8 tratamentos e 40 parcelas experimentais que possuíam as dimensões de $4,0 \times 5,0 \mathrm{~m}\left(20 \mathrm{~m}^{2}\right)$. O espaçamento entre fileiras simples foi de $0,25 \mathrm{~m}$, e entre fileiras duplas foi de $0,75 \mathrm{~m}$.

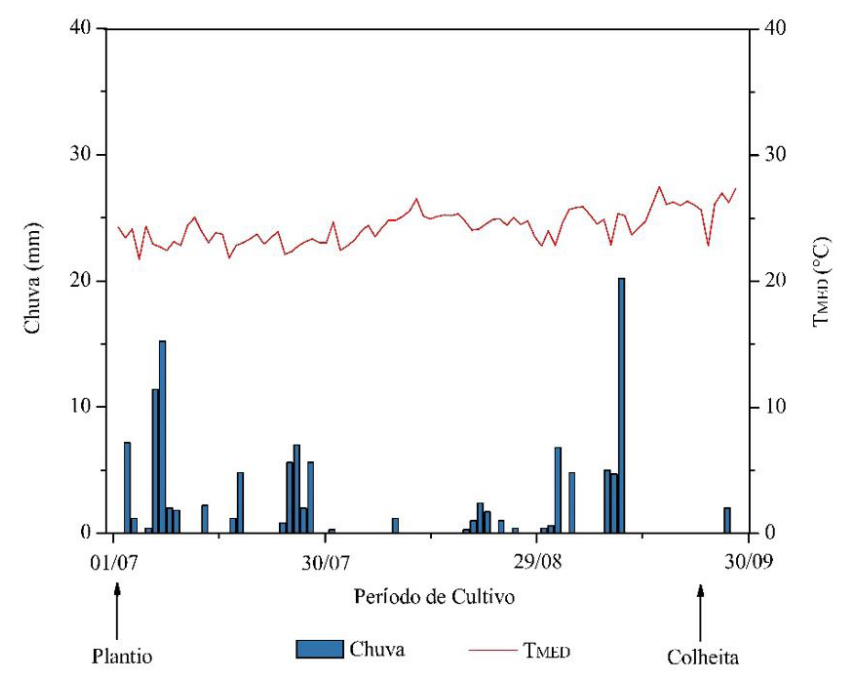

Figura 1. Temperatura média diária $-\mathrm{T}_{\mathrm{MED}}\left({ }^{\circ} \mathrm{C}\right)$ e precipitação pluvial - Chuva $(\mathrm{mm})$ durante o período experimental na região de Arapiraca, $\mathrm{AL}$. 
Tabela 1. Propriedades químicas do solo da área experimental.

\begin{tabular}{|c|c|c|c|c|c|c|c|c|c|c|c|}
\hline pH & $\mathbf{K}$ & $\mathbf{P}$ & $\mathbf{N a}$ & $\mathbf{C a}$ & Mg & Al & $\mathbf{H}+\mathbf{A l}$ & $\mathbf{F e}$ & $\mathrm{Cu}$ & Zn & Mn \\
\hline \multicolumn{3}{|c|}{----- $\mathrm{mg} \mathrm{dm}^{-3}$----- } & \multicolumn{5}{|c|}{-- $\mathrm{cmol}_{\mathrm{c}} \mathrm{dm}^{-3}$ - } & \multicolumn{4}{|c|}{ 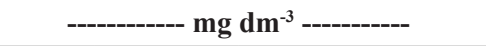 } \\
\hline 6,0 & 48 & 59 & 10 & 3,6 & 1,0 & $\mathbf{0 , 0}$ & 0,8 & 69 & 0,6 & 5,3 & 14,8 \\
\hline \multicolumn{4}{|c|}{ CTC efetiva } & \multicolumn{5}{|c|}{ V (\%) } & \multicolumn{3}{|c|}{ Matéria Orgânica Total (\%) } \\
\hline \multicolumn{4}{|c|}{3,1} & \multicolumn{4}{|c|}{79,8} & & \multicolumn{3}{|c|}{0,5} \\
\hline
\end{tabular}

A semeadura das cultivares foi realizada em $1^{\circ}$ de julho, de acordo com os espaçamentos estudados. Após a semeadura, foi aplicado herbicida pré-emergente à base de Atrazina $\left(1,5 \mathrm{~L} \mathrm{ha}^{-1}\right)$ e S-metolacloro (1,2 L ha $\left.{ }^{-1}\right)$. A adubação de fundação e cobertura foi realizada de acordo com Freire et al. (1999). Na adubação de fundação, foram aplicados $30 \mathrm{~kg} \mathrm{ha}^{-1}$ de nitrogênio $(\mathrm{N})$, $100 \mathrm{~kg} \mathrm{ha}^{-1}$ de $\mathrm{P}_{2} \mathrm{O}_{5}$ e $80 \mathrm{~kg} \mathrm{ha}^{-1}$ de $\mathrm{K}_{2} \mathrm{O}$. A adubação de cobertura foi parcelada em três aplicações nos estágios fenológicos $\mathrm{V}_{3}$, $\mathrm{V}_{6} \mathrm{e} \mathrm{V}_{9}$, e nessas adubações foram aplicados os $70 \mathrm{~kg}$ restantes para um total de $100 \mathrm{~kg} \mathrm{ha}^{-1}$ de $\mathrm{N}$.

Foi realizada irrigação pelo sistema de gotejamento, com emissores espaçados em $20 \mathrm{~cm}$ e vazão média de $2,1 \mathrm{~L} \mathrm{~h}^{-1}$. O turno de rega foi diário, e a lâmina líquida de água aplicada foi determinada de acordo com a evapotranspiração da cultura $\left(\mathrm{ET}_{\mathrm{C}}\right)$ obtida pela Equação 1.

$E T_{C}=E T o * K c$

em que, $\mathrm{ET}_{0}$ é a evapotranspiração de referência estimada pelo método de Penman-Monteith-FAO (ALLEN et al., 1998), e $\mathrm{K}_{\mathrm{C}}$ é o coeficiente da cultura.

$\mathrm{O} \mathrm{K}_{\mathrm{C}}$ do milho doce variou em função do desenvolvimento fenológico da planta. $\mathrm{Na}$ fase vegetativa da cultura, o valor adotado foi 0,5 , na floração foi 0,9 , e na frutificação e senescência o $\mathrm{K}_{\mathrm{C}}$ foi 1,2 e 1,1, respectivamente, conforme Doorenbos e Kassam (1979).

A colheita foi realizada em 20 de setembro de 2018, 81 dias após a semeadura, quando as plantas estavam no estágio fenológico $\mathrm{R}_{3}$, caracterizado por espigas com grãos pastosos, propícios para processamento agroindustrial. Em seis plantas da área útil da parcela foram avaliadas as seguintes variáveis: diâmetro de espigas sem palha ( $\mathrm{mm})$, comprimento de espigas sem palha $(\mathrm{cm})$, número de fileiras de grãos por espigas, número de grãos por fileira de espigas, produtividade de espigas sem palha $\left(\mathrm{t} \mathrm{ha}^{-1}\right)$, produtividade de grãos $\left(\mathrm{t} \mathrm{ha}^{-1}\right), \mathrm{pH}$ e teor de Brix do extrato de grãos. $\mathrm{O}$ comprimento de espigas foi obtido por meio de uma fita métrica, e o diâmetro foi medido com paquímetro digital na região central das espigas. A pesagem de espigas e dos grãos foi feita em uma balança digital com precisão de $0,001 \mathrm{~g}$, e a partir do peso de grãos por planta obtido, foi realizada a estimativa da produtividade agrícola de grãos em função da população de plantas por hectare, de acordo com os espaçamentos estudados. Os grãos foram separados do sabugo com auxílio de um debulhador de milho verde (Mecamau, D-032, Espírito Santo do Pinhal, Brasil).

Para determinar o $\mathrm{pH}$ e o teor de sólidos solúveis totais (Brix) do extrato de grãos de milho doce, utilizaram-se $40 \mathrm{~g}$ de grãos de milho que, misturados a $40 \mathrm{~mL}$ de água destilada, foram processados em liquidificador até formar uma solução homogênea. Em seguida, foi aferido o pH no aparelho HI 2221 Calibration Check pH e o Brix obtido através de um refratômetro portátil analógico (Pocket Refractometer PAL-3).

Os dados coletados foram submetidos à análise de variância e, quando significativos pelo teste $\mathrm{F}(\mathrm{P}<0,05)$, foram submetidos a análise de regressão para o fator espaçamento entre plantas e teste de Tukey $(\mathrm{P}<0,05)$ para o fator cultivares de milho doce.

\section{Resultados e Discussão}

Entre as cultivares, houve efeito significativo, a 5\% de probabilidade, para as variáveis: diâmetro de espigas sem palha, comprimento de espigas sem palha, produtividade de grãos, $\mathrm{pH}$ e teor de Brix de grãos. Os espaçamentos entre plantas estudados geraram efeito significativo, a $5 \%$ de probabilidade, para as variáveis: diâmetro de espigas sem palha, comprimento de espigas sem palha e produtividade de grãos. A interação entre os fatores estudados não foi significativa para as variáveis analisadas. As demais variáveis não foram significativas. A análise de variância encontra-se na Tabela 2 .

As cultivares utilizadas na pesquisa apresentaram valores de componentes de produção distintos. O diâmetro médio de espigas sem palha (DESP) em áreas cultivadas com a cultivar SV9298 PRO foi de 52,1 mm, enquanto a cultivar Thunder obteve um diâmetro de espigas médio de 49,6 mm. Portanto, SV9298 PRO proporcionou um incremento de 5\% no diâmetro de espigas sem palha em relação a Thunder. Quanto ao comprimento médio de espigas sem palha (CESP), SV9298 PRO apresentou o maior valor de $20,2 \mathrm{~cm}$, e isso representa um valor $10 \%$ maior que o comprimento de espigas sem palha apresentado pela Thunder, que foi de 18,3 cm. Rodrigues et al. (2018) afirmam que o comprimento e o diâmetro de espigas são as principais características levadas em consideração no mercado consumidor para compra de espigas verdes. Os pesquisadores ratificam que o mercado exige espigas de comprimento superior a $15 \mathrm{~cm} \mathrm{e}$ diâmetro maior que $30 \mathrm{~mm}$, corroborando os valores obtidos nesta pesquisa, o que indica que as duas cultivares nas condições edafoclimáticas do cultivo tendem a produzir espigas com padrão comercial aceitável, destacando-se a cultivar SV9298 PRO por apresentar maiores medidas quando comparada à cultivar Thunder (Tabela 3).

A menor produtividade média de grãos $(\mathrm{PG})$ foi produzida em áreas cultivadas com Thunder, 10,7 tha ${ }^{-1}$, e a maior produtividade foi de 13,3 t ha-1, nas áreas de SV9298 PRO, o que significa um incremento de $24 \%$ na PG. Luz et al. (2014) avaliaram a produtividade de grãos de genótipos de milho doce em função de intervalos de colheita e obtiveram a maior produtividade de 
Tabela 2. Análise de variância das variáveis, diâmetro de espigas sem palha (DESP), comprimento de espigas sem palha (CESP), número de fileiras de grãos por espigas (NFE), número de grãos por fileira de espigas (NGF), produtividade de espigas sem palha (PESP), produtividade de grãos (PG), teor de Brix e $\mathrm{pH}$ de cultivares de milho doce sob espaçamentos entre plantas em fileiras duplas.

\begin{tabular}{|c|c|c|c|c|c|}
\hline \multirow{2}{*}{ Fontes de Variação } & \multirow{2}{*}{ GL } & \multicolumn{4}{|c|}{ Quadrados Médios } \\
\hline & & DESP & CESP & NFE & NGF \\
\hline Cultivar (C) & 1 & $64,05 * *$ & $38,78 * *$ & $0,00^{\mathrm{ns}}$ & $31,22^{\mathrm{ns}}$ \\
\hline Espaçamento (E) & 3 & $14,22 *$ & $1,63 * *$ & $0,80^{\mathrm{ns}}$ & $21,63^{\text {ns }}$ \\
\hline $\mathbf{C} \times \mathbf{E}$ & 3 & $5,10^{\text {ns }}$ & $0,64^{\mathrm{ns}}$ & $0,19^{\text {ns }}$ & $3,44^{\text {ns }}$ \\
\hline Bloco & 4 & $17,16^{\text {ns }}$ & $4,29^{\mathrm{ns}}$ & $0,01^{\text {ns }}$ & $10,02^{\mathrm{ns}}$ \\
\hline Resíduo & 36 & 3,56 & 0,66 & 0,39 & 5,03 \\
\hline \multirow[t]{2}{*}{ CV $(\%)$} & & 3,67 & 3,51 & 3,88 & 6,58 \\
\hline & & PESP & PG & BRIX & pH \\
\hline Cultivar (C) & 1 & $353033,73^{\text {ns }}$ & $6714242,95 * *$ & $176,40 * *$ & $0,63 * *$ \\
\hline Espaçamento (E) & 3 & $30460567,45^{\mathrm{ns}}$ & $4993824,80 * *$ & $21,50^{\text {ns }}$ & $0,01^{\mathrm{ns}}$ \\
\hline $\mathbf{C} \times \mathbf{E}$ & 3 & $664367,22^{\text {ns }}$ & $580244,23^{\text {ns }}$ & $9,72^{\text {ns }}$ & $0,01^{\text {ns }}$ \\
\hline Blocos & 4 & $28870029,05^{\text {ns }}$ & $538151,13^{\mathrm{ns}}$ & $80,37^{\text {ns }}$ & $0,17^{\mathrm{ns}}$ \\
\hline Resíduo & 36 & 46483984,20 & 7175997,48 & 10,10 & 0,02 \\
\hline CV $(\%)$ & & 34,50 & 22,80 & 26,40 & 2,36 \\
\hline
\end{tabular}

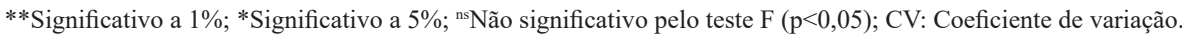

Tabela 3. Teste de média de variáveis significativas, diâmetro de espigas sem palha (DESP), comprimento de espigas sem palha (CESP), produtividade de grãos (PG), pH e teor de Brix de cultivares de milho doce.

\begin{tabular}{|c|c|c|c|c|c|}
\hline \multirow{2}{*}{ CULTIVARES } & DESP & CESP & PG & pH & BRIX \\
\hline & $\mathbf{m m}$ & cm & $\mathbf{t h a}^{-1}$ & - & - \\
\hline SV9298 PRO & 52,16 a & 20,29 a & 13,31 a & 7,05 a & 13,57 a \\
\hline THUNDER & $49,63 \mathrm{~b}$ & 18,32 b & $10,71 \mathrm{~b}$ & $6,82 \mathrm{~b}$ & 9,37 b \\
\hline
\end{tabular}

Médias significativas a $5 \%$ de probabilidade pelo teste de Tukey.

11,7 t ha ${ }^{-1}$ em Uberlândia, MG. Os pesquisadores afirmam que a produtividade de grãos é o componente de produção mais importante no cultivo de milho, e determinar a capacidade produtiva de genótipos sob as diversas condições edafoclimáticas do país é importante para expansão da cultura. Diante do exposto, observa-se que a produtividade de grãos máxima obtida pelos pesquisadores se aproxima da maior produtividade obtida nesta pesquisa, e isso confirma o potencial produtivo do milho doce no Agreste alagoano com irrigação, tendo sua demanda evapotranspiratória $\left(\mathrm{ET}_{\mathrm{C}}\right)$ atendida. A irrigação mostrou-se necessária devido ao ano de 2018 ter sido atípico em relação à média pluviométrica da região.

$\mathrm{O}$ maior $\mathrm{pH}$ de grãos médio na pesquisa foi de 7,0, obtido com a cultivar SV9298 PRO. A cultivar Thunder obteve o pH médio de 6,8 , o que significa uma redução de $3 \%$ no valor médio de pH de grãos de milho doce. Mamede et al. (2014) realizaram análise físico-química de grãos de milho doce e obtiveram $\mathrm{pH}$ médio de 7,1, valor próximo ao $\mathrm{pH}$ de grãos das cultivares utilizadas nesta pesquisa. Quanto ao teor de Brix, o maior valor médio foi de $13,5^{\circ} \mathrm{Brix}$, obtido em áreas com a cultivar SV9298 PRO, enquanto áreas cultivadas com Thunder obtiverem um valor médio de $9,3{ }^{\circ}$ Brix. Isso significou uma redução de $31 \%$ no teor de Brix de grãos em relação ao valor obtido pela cultivar SV9298 PRO. Perfeito et al. (2017) estudaram características pós-colheita da cultivar Doce Cristal e obtiveram um teor de Brix máximo $15^{\circ}$ Brix. Os autores indicaram que esse valor é satisfatório para o milho doce, pois o maior teor de Brix, aliado a um $\mathrm{pH}$ próximo da neutralidade, realça o sabor (doçura) do milho doce, o que gera maior palatabilidade e aceitação do público consumidor. Portanto, fica nítido que o pH e o Brix apresentados pela cultivar SV9298 PRO são tidos como aceitáveis e desejáveis para comercialização de milho doce de boa qualidade, e superaram os valores apresentados pela cultivar Thunder.

Os diferentes espaçamentos entre plantas em fileira dupla provocaram efeito significativo no diâmetro de espigas sem palha (DESP). O maior diâmetro de espigas $(52,3 \mathrm{~mm})$ foi obtido em áreas cultivadas no espaçamento entre plantas de $35 \mathrm{~cm}$, e o menor diâmetro $(46,25 \mathrm{~mm})$ foi obtido sob o espaçamento de $20 \mathrm{~cm}$ entre plantas; assim, o espaçamento de $35 \mathrm{~cm}$ proporcionou um incremento de $13 \%$ no diâmetro de espigas do milho doce em relação ao menor espaçamento estudado de $20 \mathrm{~cm}$ (Figura 2a). Quanto ao comprimento de espigas sem palha (CESP), o maior valor obtido foi de $19,5 \mathrm{~cm}$ no espaçamento de $35 \mathrm{~cm}$ entre plantas, e isso representou um incremento de $4 \%$ em relação ao menor valor no espaçamento de $20 \mathrm{~cm}$, o qual ficou em torno de obtido de 18,8 cm. (Figura 2b). Silva et al. (2019) estudaram componentes de produção de híbridos de milho verde sob diferentes espaçamentos em Goiás e concluíram que espaçamentos interferem em componentes de produção do milho, como comprimento e diâmetro de espigas, e isso gera maior peso de espigas com e sem palha. Os pesquisadores atribuem esse ganho produtivo ao fato de que os diferentes espaçamentos proporcionam menor ou maior competição por água, radiação e nutrientes entre plantas na área de cultivo. Portanto, a determinação do espaçamento ideal que alie aumento dos valores de componentes de produção e número de planta é importante para o sucesso e a lucratividade da cultura. Os 

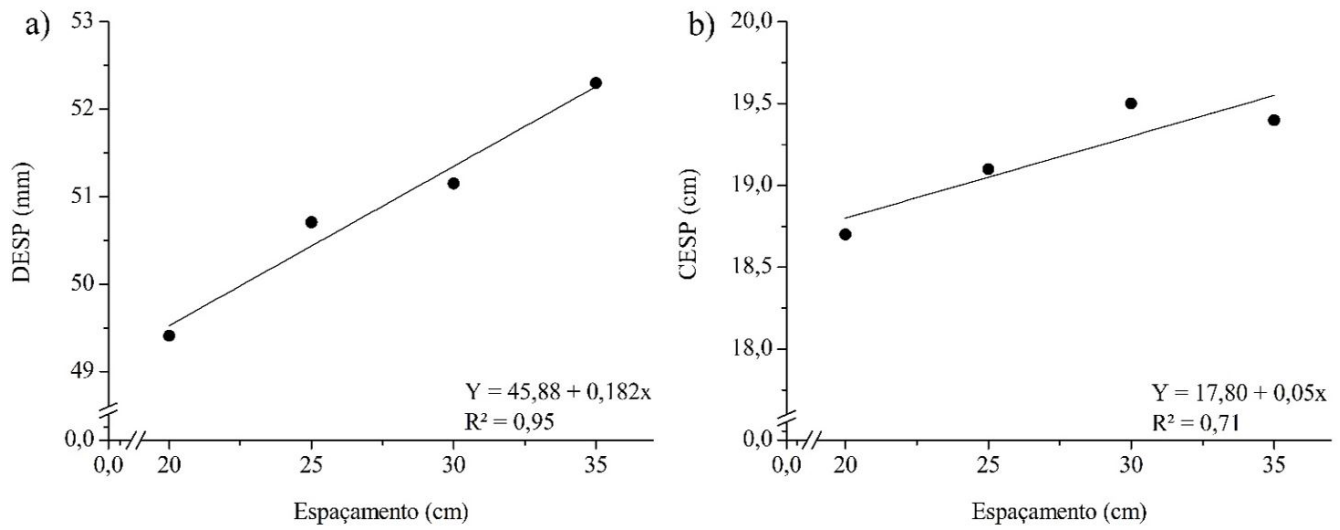

Figura 2. Diâmetro de espigas sem palha - DESP (a) e comprimento de espigas sem palha - CESP (b) de milho doce sob diferentes espaçamentos entre plantas em fileiras duplas.

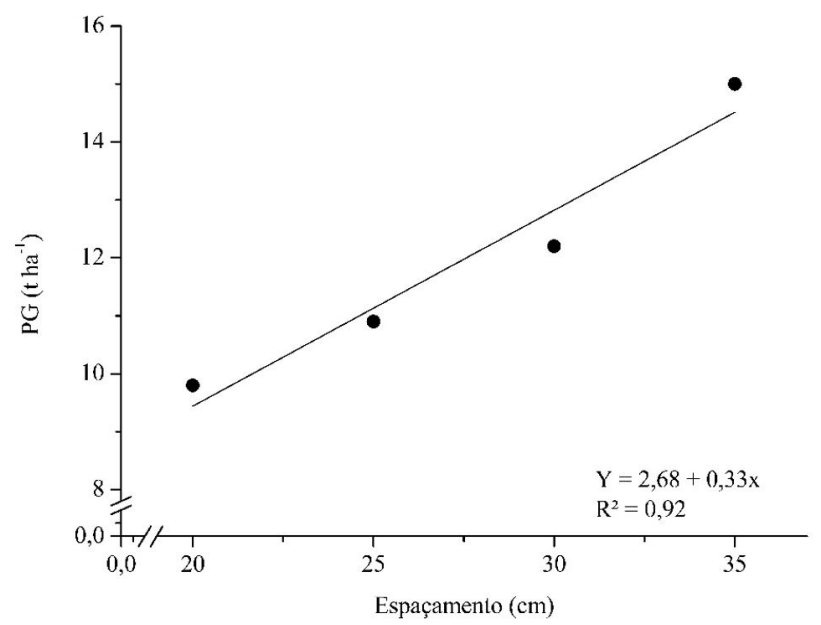

Figura 3. Produtividade de grãos - PG de milho doce sob diferentes espaçamentos entre plantas em fileiras duplas.

resultados confirmados pelos pesquisadores corroboram os dados desta pesquisa, em que o milho doce sob o maior espaçamento estudado $(35 \mathrm{~cm})$ obteve maiores componentes de produção, como comprimento e diâmetro de espigas. Isso possivelmente ocorreu em razão da menor competição entre plantas por água, radiação e nutrientes essenciais.

A maior produtividade de grãos (PG) foi de $14,2 \mathrm{tha}^{-1}$ quando cultivado no espaçamento de $35 \mathrm{~cm}$ entre plantas. Enquanto, no espaçamento de 20 entre plantas, a produtividade de grãos foi de apenas $9,2 \mathrm{tha}^{-1}$. Portanto, o maior espaçamento utilizado nesta pesquisa proporcionou um incremento na produção de grãos de $53 \%$ em relação à menor produtividade obtida em áreas com o espaçamento de $20 \mathrm{~cm}$ (Figura 3). Diversos pesquisadores ratificam que diferentes arranjos populacionais de plantas podem gerar maior incremento na produtividade de grãos da cultura do milho (CALONEGO et al., 2011; FUMAGALLI et al., 2017; MUBARAK et al., 2020). Os pesquisadores afirmam que há uma relação delicada entre o número de plantas ideal por área a fim de maximizar a produtividade de grãos de milho, e que maiores espaçamentos entre plantas tendem a favorecer o crescimento da cultura, com plantas mais vigorosas e produtivas. Diante disso, observa-se que o milho doce apresenta uma resposta produtiva satisfatória sob maiores espaçamentos, possivelmente pelo fato de a cultura ser mais exigente em água, luz e nutrientes do que o milho comum, demonstrando maior potencial produtivo sob baixa competição.

De modo geral, foi observado aumento produtivo do milho doce sob espaçamentos crescentes entre plantas (de 20 a $35 \mathrm{~cm}$ ), e isso resultou em maior produtividade de grãos. Quanto às cultivares, foi observado que a cultivar SV9298 PRO proporciona espigas mais desejáveis comercialmente em relação à cultivar Thunder.

Os dados confirmam a importância em compreender o comportamento produtivo de cultivares de milho doce sob diferentes espaçamentos de plantio para que seja aplicado o adequado manejo à cultura, principalmente na região onde o estudo foi desenvolvido, em que é comum realizar o plantio de forma empírica e com cultivares pouco produtivas. Também se torna importante ressaltar que, apesar dos resultados mais promissores da cultivar SV9298 PRO, são necessárias mais pesquisas na região, buscando consolidar a cultivar com melhores atributos produtivos.

\section{Conclusões}

A cultivar de milho doce SV9298 PRO produz espigas de maior comprimento $(20,2 \mathrm{~cm})$, diâmetro $(52,1 \mathrm{~mm})$ e produtividade de grãos $\left(13,3 \mathrm{tha}^{-1}\right)$.

As características pós-colheita de $\mathrm{pH}$ e teor de Brix são maiores em áreas cultivadas com SV9298 PRO, sendo, respectivamente, 7,0 e $13,5^{\circ}$ Brix.

$\mathrm{O}$ espaçamento entre plantas de $35 \mathrm{~cm}$ proporciona maior comprimento $(19,5 \mathrm{~cm})$, diâmetro de espigas sem palha $(52,3 \mathrm{~mm})$ e maior produtividade de grãos $\left(14,2 \mathrm{t} \mathrm{ha}^{-1}\right)$.

\section{Referências}

ALLEN, R. G. et al. Crop evapotranspiration: guidelines for computing crop requeriments. Roma: Organização das Nações Unidas para Alimentação e Agricultura (FAO), 1998. 328 p. 
BARROS, A. H. C. et al. Climatologia do estado de Alagoas. Recife: Embrapa Solos, 2012. 32 p. n. 211.

BRASIL. Ministério da Agricultura, Pecuária e Abastecimento. Projeções do Agronegócio: Brasil 2017/18 a 2027/28 projeções de longo prazo. Brasília: MAPA/ACE, 2018.

BRASIL. Ministério da Agricultura, Pecuária e Abastecimento. Registro Nacional de Cultivares. Brasília: CSM/DFIA/SDA, 2020.

CALONEGO, J. C. et al. Produtividade e crescimento de milho em diferentes arranjos de plantas. Agrarian, Dourados, v. 4, n. 12, p. 84-90, 2011.

CARVALHO, M. N.; NAKAGAWA, J. Sementes: ciência, tecnologia e produção. Jaboticabal: Funep, 2012. 590 p.

DOORENBOS, J.; KASSAM, A. H. Yield response to water. Rome: FAO, 1979. (FAO Irrigation and Drainage Paper, 33).

FOOD AND AGRICULTURE ORGANIZATION - FAO. Organização das Nações Unidas para alimentação e agricultura. Rome, 2012. Disponível em: $<$ http://www.fao.org/faostat/en/\#data/QC $>$. Acesso em: 28 fev. 2021.

FREIRE, F. M. et al. In: RIBEIRO, A. C.; GUIMARÃES, P. T. G.; ALVAREZ, V. V. H. Recomendações para o uso de corretivos e fertilizantes em Minas Gerais. Viçosa: Comissão de Fertilidade do Solo do Estado de Minas Gerais, 1999. p. 43-60.

FUMAGALLI, M. et al. Desempenho produtivo do milho híbrido simples em função de espaçamentos entre fileiras e populações de plantas. Revista Brasileira de Milho e Sorgo, Sete Lagoas, v. 16, n. 3, p. 426-439, 2017. http://dx.doi.org/10.18512/1980-6477/ rbms.v16n3p426-439.

KÖPPEN, W. Climatologia: con un estudio de los climas de la tierra. México: Fundo de Cultura Econômica, 1948. 498 p.

LUZ, J. M. Q. et al. Produtividade de genótipos de milho doce e milho verde em função de intervalos de colheita. Horticultura Brasileira, Recife, v. 32, n. 2, p. 163-167, 2014. http://dx.doi.org/10.1590/ S0102-05362014000200007.
MAMEDE, A. M. G. N. et al. Qualidade do milho doce minimamente processado conservado sob diferentes atmosferas. Engenharia na Agricultura, Viçosa, v. 22, n. 6, p. 520-534, 2014. http://dx.doi. org/10.13083/reveng.v22i6.583.

MANTOVANI, E. C. et al. Avaliação em campo de uma semeadoraadubadora para plantio de milho de alta densidade. Revista Brasileira de Milho e Sorgo, Sete Lagoas, v. 14, n. 1, p. 38-48, 2015.

MUBARAK, I. et al. Triple-row system with a wider drip-line lateral spacing for two drip-irrigated sweet corn cultivars. Pesquisa Agropecuária Brasileira, Brasília, v. 55, p. 1-9, 2020. http://dx.doi. org/10.1590/s1678-3921.pab2020.v55.01684.

PEREIRA FILHO, I. A.; BORGHI, E. Sementes de milho no Brasil: a dominância dos transgênicos. Sete Lagoas: Embrapa Milho e Sorgo, 2018. (Documentos, 223).

PERFEITO, D. G. A. et al. Caracterização pós-colheita de milho doce submetido ao parcelamento de fertirrigação nitrogenada. Brazilian Journal of Food Technology, Campinas, v. 20, p. 1-7, 2017. http:// dx.doi.org/10.1590/1981-6723.14016.

RODRIGUES, F. et al. Aptidão de híbridos de milho para o consumo in natura. Revista de Ciências Agrárias, Lisboa, v. 41, n. 2, p. 484-492, 2018. http://dx.doi.org/10.19084/RCA17216.

SILVA, D. P. et al. Análise de crescimento de híbridos milho verde irrigado em resposta a espaçamentos no cerrado. Revista Agrotecnologia, Goiás, v. 10, n. 1, p. 62-71, 2019. http://dx.doi. org/10.12971/2179-5959/agrotecnologia.v10n1p62-71.

SILVA, R. F. et al. Produção de espigas de milho verde irrigado sob influência do espaçamento e da densidade de plantas. Revista Brasileira de Agricultura Irrigada, Fortaleza, v. 14, n. 1, p. 3835-3843, 2020. http://dx.doi.org/10.7127/rbai.v14n1001079.

ZUCARELI, C. et al. Qualidade fisiológica de sementes de milho doce classificadas pela espessura e largura. Pesquisa Agropecuária Tropical, Goiânia, v. 44, n. 1, p. 71-78, 2014. http://dx.doi. org/10.1590/S1983-40632014000100009.

Recebido: 20 mar. 202 Aprovado: 20 mar. 2021 